\title{
Research on Financial Risk Management Based on VAR Model
}

\author{
Xingchen $\mathrm{Li}^{*}$ \\ Economics and Management School, Wuhan University, Wuhan, Hubei, China
}

\begin{abstract}
VaR is a widely- applied tool in the international financial risk management area, and it is also a new technical standard for measuring financial risk. VAR model was first used to measure market risk. Currently VAR analysis methods are gradually being introduced in all areas of financial risk management. VAR model in financial risk management uses more widely. Especially with the continuous improvement of the VAR model, it can be apply to financial institutions, market risk, credit risk management. And it has a wide range of applications in the liquidity risk management and financial regulation and so on. Based on this, we In-depth discuss financial risk management based on VAR model.
\end{abstract}

Keywords: Financial risk management, value at risk (VaR), VAR model.

\section{INTRODUCTION}

In recent years, with the rapid development of financial markets, the risks faced by financial institutions is becoming more complex. The main risk has turned credit risk to the market risk. Performance shows the composite interest rate risk, price risk and exchange rate risk. China's financial market is a developing emerging markets. It is necessary to establish China's financial market risk prediction model to adapt to China's financial risk management. In the 1990s, Value at Risk (VaR) model [1-4], was introduced financial risk management. Because of its financial market risk measurement science, practical features, it has been generally welcomed, including financial regulators and the international financial community.

To the VaR of a modern financial market risk measurement, management methods may be different market factors, the risk of different combinations of assets to be integrated sum. Fully consider the interaction of the various sources of risk, to better reflect the dynamic impact of the financial market risks between complex structures, to get a more accurate estimate of the risk of exposure [5-8]. Based on this, we In-depth discuss financial risk management based on VAR model. So that we deepen the VAR model used in financial risk management.

\section{THE BASIC CONTENTS OF VAR MODEL}

Under normal market fluctuations, at a certain probability level, VaR [1] refers to financial assets of a maximum possible losses or a combination of securities in the future a specific period of time. VaR value can be used to concisely represent the size of the market risk. So there is no professional background investors and managers to be available through the financial risk VaR value judgment. VaR can calculate methods and risk beforehand. Unlike previous methods of risk management to measure the size of the risk, VAR method is in hindsight. In addition, VaR method can also measure the overall risk of the entire portfolio, which the traditional financial risk management can not do. These features of VaR measure makes it gradually become the mainstream method of financial risk. More and more financial institutions use VaR to measure market risk, the use of VaR as risk limits. In particular, the regulatory authorities are determined using the VaR risk capital $[9,10]$. This makes a lot of financial institutions and the business sector in the investment choices often need to meet the VaR constraint.

According to the above definition, computing VAR values generally requires the following three factors: confidence interval; holding period; distribution of asset prices. Confidence intervals and the holding period for selection is based on the principles of risk appetite of financial institutions and the soundness of the decision makers. During calculating VAR, the most critical is the distribution of asset prices. VAR is $E(W)$ (the end of the period of the mean value) minus the $W^{*}$ (ending value of the minimum value of the mean value).

$$
\begin{aligned}
& V A R=E(W)-W^{*} \\
& V A R=W_{0}\left(E(R)-R^{*}\right)
\end{aligned}
$$

Among them, $W_{0}$ is the value at the beginning of the portfolio. $R$ is the rate of return. $W=W_{0}(1+R)$ is the ending value of the investment portfolio. $W^{*}=W_{0}\left(1+R^{*}\right)$ is the minimum value in the degree of confidence. Under normal circumstances, there are three methods [2] to calculate the value of VAR: the variance - covariance method; historical simulation method; Monte Carlo simulation method.

The basic idea covariance method - the variance is: Using historical data to calculate the portfolio returns variance and covariance; Income portfolio assumes a normal distribution, 


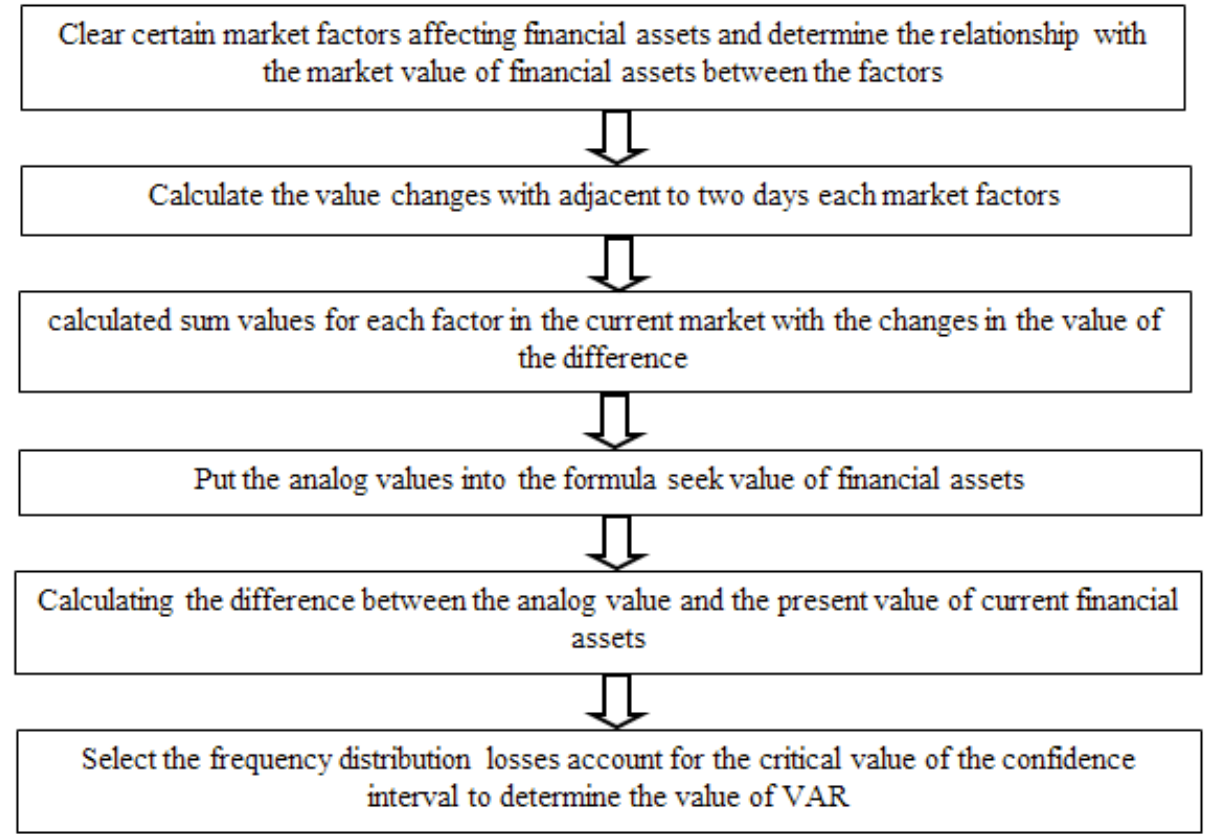

Fig. (1). The specific steps of historical simulation method.

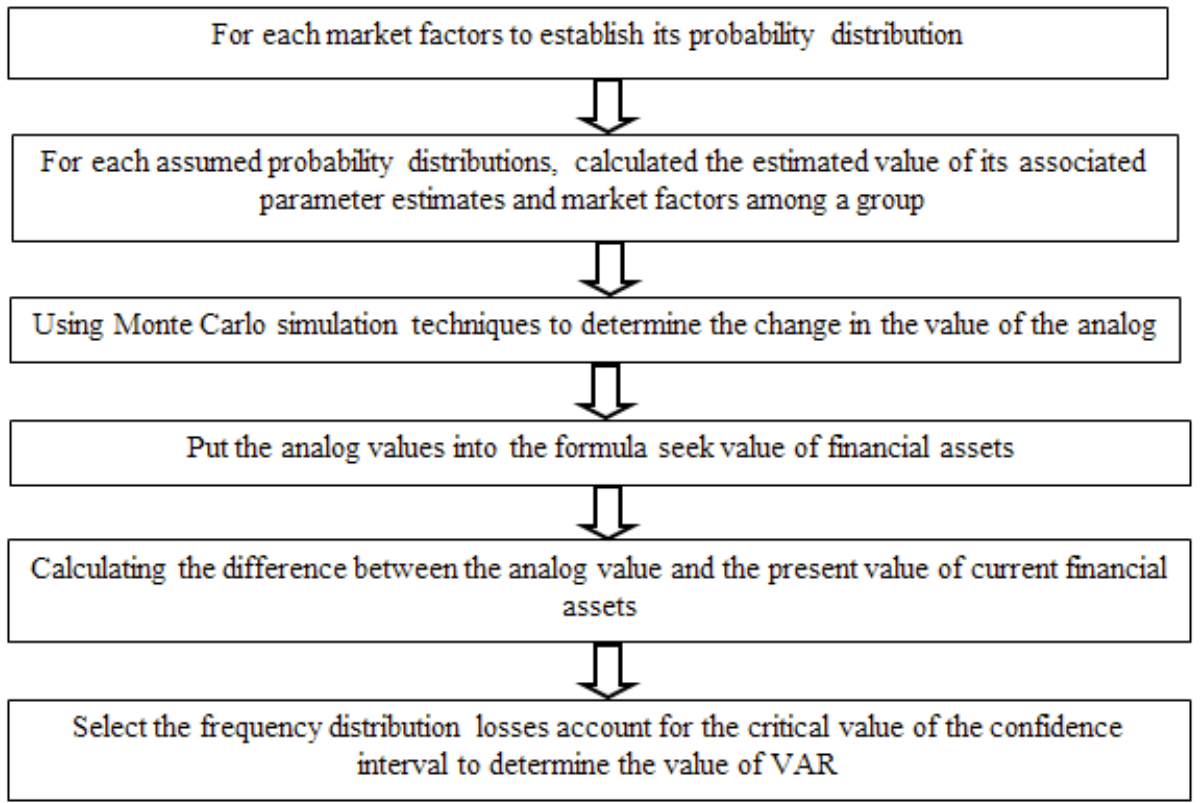

Fig. (2). Monte carlo simulation method's steps.

calculated at a certain level of confidence to reflect the distribution of the degree of deviation from the mean of the critical value; Establish contact with the risk of loss. VAR value is derived. So we can find $R$ under Confidence. Using (2), can be obtained VAR.

Historical simulation method uses changes in market factors in a given historical period observed to indicate future changes in market factors. The specific steps is shown as Fig. (1).

From the Fig. (1), according to the future price level market factors revaluation of positions, we calculate the value of the change in the position of (profit and loss); Finally, the nally, the combination of gains and losses from the smallest to the largest sort, get the profit and loss distribution, through to quantile under the given confidence level calculated VAR.

Monte Carlo simulation method, also known as stochastic simulation method. The basic idea is that in order to solve the problem of economic and financial aspects, first establish a probability model or a random process, making it the parameter be equal to solution of the problem. Standard deviation is then calculated by observing the model or process parameters which are seeking statistical characteristics. Finally, asking questions approximation accuracy of the solution can be expressed with an estimated value. he specific steps is shown as Fig. (2). 
In all, from those methods, we can calculate VAR.

\section{VAR MODEL IN FINANCIAL RISK MANAGE- MENT}

With the establishment and improvement of China's socialist market economy under the financial markets, excessive administrative intervention in the market will gradually shift focus on market regulation, and market risk will be more exposed to the front of the economy. So the use of VaR method can provide an effective market risk management tools for our financial institutions and investors, but also to provide a scientific risk management standards for the People's Bank, the Commission and other financial regulators.

Risk positions of various financial assets[3] can be divided into "linear" and "non-linear" categories. Linear and non-linear relationship means that the potential benefits and value of the asset position of relative changes between whether is linear.

At present, China's financial markets in a simple linear positions in investment vehicles accountes for the majority of trading products. The amount of financial derivatives business is less, where the nonlinear domestic derivatives trading is still blank. But with the opening up of China's financial services sector, increased market risk, derivatives trading volume will rise. Options are non-linear derivatives. It is a right of choice rather than a business. The option holder has the right to determine the time at a price determined by the sale of a certain underlying financial assets. Options under the direction of the trade can be divided into a call option (right to buy) and a put option. $X$ is the strike price. $C_{u}$ is the call option price. Bullish yields within $T-f$ time is:

$R=\frac{\max \left(0, S_{T}-X\right)}{C_{u}-1}$

Definition and implementation of the price corresponding to the confidence level $T_{x}$

$1-T_{x}=P\left(S_{T}<X\right)=P\left[\ln S_{T}-\ln S<\ln (X-S)\right]$

Call option value at risk indicators:

$\left.\operatorname{VaR}=C_{u}(T-t)-R^{*}\right\rfloor$

Puts value at risk indicators:

$\operatorname{VaR}=C_{d}\left[(T-t)-R^{*}\right\rfloor$

$C_{d}$ is Put Price.

Through computational analysis shows that when the portfolio of options portfolio constituted portfolio face greater financial risk, we should promptly adjust the investment portfolio. It yields is close to a normal distribution. Control the size of the portfolio VaR value to reduce risk.

Although VaR model is widely used in financial risk management, but it is not a panacea for risk management, but also has its limitations. Specific application should pay attention to the following aspects of the problem: VaR model series of assumptions make the model subject to certain restrictions in the application; VaR model has the same model with other models of risk. In estimating the risk to select the appropriate statistic. If the statistics selected properly, will lead to increased prediction error. Therefore, the model should be tested statistic; VaR model does not consider the extreme case. But the market is effectively measuring risk under normal fluctuation. Extreme changes in financial losses caused by the market price can not be measure. We must rely on stress tests and other methods.

\section{CONCLUSION}

Finance is the core of modern economy. With the development of financial globalization, financial market risk management has gradually been paying attention. The research on the financial risk is also largely qualitative based. And on the international financial markets generic qualitative and quantitative modeling of the integrated application of risk management practices have a large gap. Since VaR model can be integrated measure of financial market risk characteristics. Therefore, China's financial institutions is necessary introduced into the country, and developed to meet the needs of the actual situation of China's financial institutions.

At the same time, we must recognize the VaR model is mainly suitable for measuring market risk, and not a measure of credit risk. It is because of existing financial risk measure is not perfect, it is worth our financial institutions to learn it and study it. Emphasis should also be studied theories, methods and technical standards of China's financial risk management, in order to enhance the competitiveness level of our financial institutions.

\section{CONFLICT OF INTEREST}

The author confirms that this article content has no conflict of interest.

\section{ACKNOWLEDGEMENTS}

Declared none.

\section{REFERENCES}

[1] B. Huang, "Options Risk VaR Indicators Measure," vol. 19, no. 2, pp. 65-68, 2000.

[2] C. Q. Ma, H. Q. Li, and Q. Zhang, "Value at Risk Method in Use in Financial Risk Measurement," Forecast, vol. 20, no. 2, pp. 34-38, 2001

[3] P. Jorion, "Risk: Measuring the Risk in Value at Risk," Financial Analysts Journal, pp. 47-55, 1996.

[4] K. Juselius, "The cointegrated VAR model: methodology and applications," Oxford University Press, 2006.

[5] G. J. Alexander, and M. B. Alexandre, "Economic implications of using a mean-VaR model for portfolio selection: A comparison with mean-variance analysis," Journal of Economic Dynamics and Control, vol. 26, no. 7, pp. 1159-1193, 2002.

[6] J. Y. Campbell, G. Chackob, J. Rodriguezc, and M. V. Luis, "Strategic asset allocation in a continuous-time VAR model," Journal of Economic Dynamics and Control, vol. 28, no. 11, pp. 2195-2214, 2004.

[7] A. M. Khalid, and M. Kawai, "Was financial market contagion the source of economic crisis in Asia?: Evidence using a multivariate VAR model," Journal of Asian Economics, vol. 14, no. 1, pp. 131$156,2003$.

[8] J.P. Bouchaud, and M. Potters, "Theory of financial risk and derivative pricing: from statistical physics to risk management," Cambridge university press, 2003. 
[9] G. M. Bodnar, S. H. Gregory, and C. M. Richard, "Wharton survey of financial risk management by US non-financial firms, "Financial management, vol. 27, no. 4, pp. 70-91, 1998.
[10] Dolde, Walter, "The trajectory of corporate financial risk management," Journal of Applied Corporate Finance, vol. 6, no. 3, pp. 3341, 1993.

Received: June 10, 2015

Revised: July 29, 2015

Accepted: August 15, 2015

(C) Xingchen Li; Licensee Bentham Open.

This is an open access article licensed under the terms of the (https://creativecommons.org/licenses/by/4.0/legalcode), which permits unrestricted, noncommercial use, distribution and reproduction in any medium, provided the work is properly cited. 